\title{
Dilated Cardiomyopathy Caused by a Coronary- Pulmonary Fistula Treated Successfully With Coil Embolization
}

\author{
Hangyuan Guo, MD*,**; Bingquan You, MD*; Jong-Dae Lee, MD**
}

We describe a case of dilated cardiomyopathy (DCM) caused by a coronary-pulmonary fistula and myocardial ischemia induced by the coronary steal phenomenon, which was successfully treated with coil embolization. Coronary fistulae and coronary-steal-induced ischemia are rare causes of DCM in adults with normal coronary arteries. Percutaneous treatment represents an alternative to surgery and may be offered as a relatively low-risk procedure. The choice between surgical and percutaneous treatment must take into account clinical and anatomical considerations. (Circ J 2006; 70: 1223-1225)

Key Words: Coil embolization; Coronary artery fistula; Dilated cardiomyopathy; Myocardial ischemia

C oronary artery fistulas (CAF) are rare congenital anomalies with an estimated incidence of $0.2 \%-$ $0.4 \%$ of all congenital cardiac defects! The fistulas may be congenital or acquired and may communicate with a cardiac chamber, coronary sinus, vena cava, pulmonary artery (PA) or pulmonary vein. More than $90 \%$ of these fistulas open in right-sided cardiac chambers and generally connect through a single lumen, but multiple lumens with diffuse and complex connections may also occur? CAF have to be closed to prevent complications such as myocardial ischemia, congestive heart failure, infective endocarditis, aneurysm formation and, rarely, rupture! In recent years, transcatheter closure of $\mathrm{CAF}$ has emerged as a successful alternative to surgery?

\section{Case Report}

A 41-year-old man presented with either symptoms (ie, chest discomfort, palpitation and dyspnea on exertion for 3 months) and a typical continuous murmur of grade III, but neither chest pain nor syncope and no history of hypertension. Chest X-ray showed general enlargement of the heart shadow (Fig 1). On the initial electrocardiogram, there was evidence of left ventricular hypertrophy $(\mathrm{LVH})$ and strain (Fig 2). CAF could not be detected by color Doppler echocardiography, although the echocardiograms (Fig 3) showed left ventricular $(\mathrm{LV})$ enlargement $(6.2 \mathrm{~cm})$, abnormal ventricular function and wall motion (ejection fraction: $41.8 \%$; fractional shortening: $24 \%$ ), but normal LV wall thickness.

Selective coronary angiography was performed to determine the anatomy of the fistula and feasibility of trans-

(Received March 30, 2006; revised manuscript received June 12, 2006; accepted June 28, 2006)

*Department of Cardiology, Shaoxing People's Hospital, The First Affiliated Hospital of Medical College, Shaoxing University, Shaoxing, Zhejiang, China, **First Department of Internal Medicine, Medical College, Fukui University, Fukui, Japan

Mailing address: Hangyuan Guo, MD, PhD, Department of Cardiology, Shaoxing People's Hospital, The First Affiliated Hospital of Medical College, Shaoxing University, Shaoxing, Zhejiang 312000,

China. E-mail: ghangyuan@hotmail.com catheter closure (Fig 4A). A selective injection was then performed without balloon occlusion to delineate precisely the diameter of the fistula, its drainage site and identify all distal coronary branches. The origin of the fistula was from the left anterior descending (LAD) coronary artery to the PA (Fig 4B). The fistula was closed successfully with 4 Gianturco coils (Figs 4C,D). There were no major complications such as coil migration, dissection of native coronary arteries or of the feeding vessel, myocardial infarction, death, stroke or infection. The patient has been followed up clinically and by echocardiography 3 months after the procedure and he has been asymptomatic with no clinically audible murmurs. Echocardiography (Fig 5) at the end of the 3 months showed a reduced LV diameter $(5.0 \mathrm{~cm})$ and improved ventricular function and wall motion (ejection fraction: 58.1\%; fractional shortening: $31 \%$ ). We measured the changes in hemodynamics before and 3 months after treatment, such as PA pressure by echo, oxygen saturation in the aorta, PA and right atrium by catheter, shunt ratio, plasma levels of brain natriuretic peptide and carnitine (Table 1).

\section{Discussion}

The first description of CAF was given by Krause in

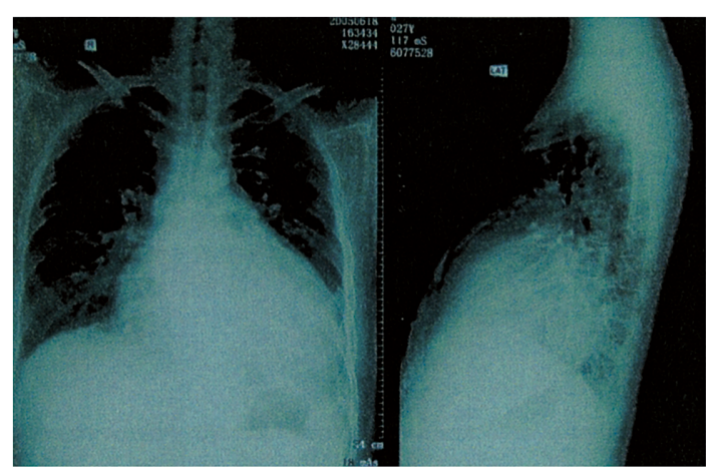

Fig 1. Chest X-ray (anteroposterior and lateral positions). 

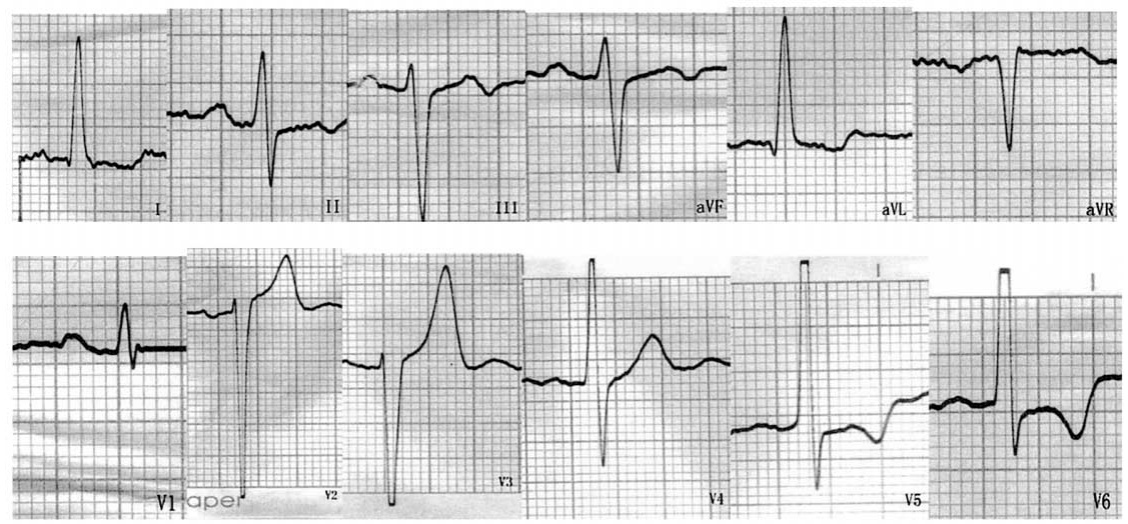

Fig 2. Electrocardiogram showing left ventricular hypertrophy and strain.
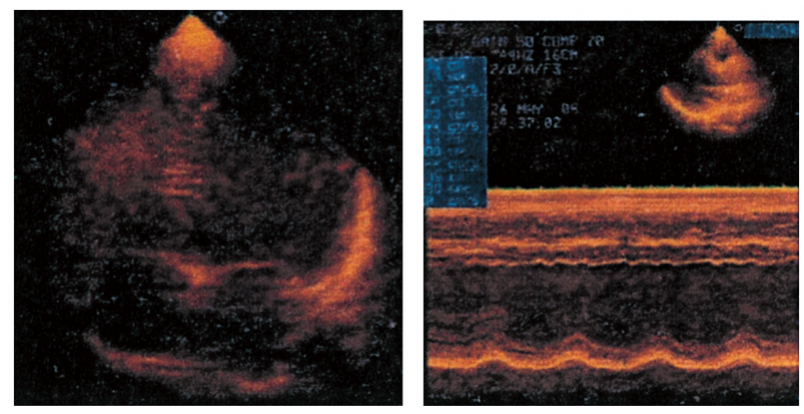

Fig 3. Echocardiography findings (pre-operation).

1865 and it is classified as primary and secondary. Primary fistulas occur in association with congenital heart lesions, such as pulmonary atresia with intact ventricular septum, or as an isolated lesion in an otherwise normal heart. Acquired CAF can occur as a result of intracardiac operations or following transcatheter interventions such as myocardial biopsy or coronary angioplasty5 CAF mostly originate from the right coronary artery and drain into the right heart or PA. Bilateral fistulas originating from the right and left coronary arteries account for only 5\% of all fistulas and tend to terminate in the PA. Congenital CAF $(3 \%)$ rarely drain into the left heart and when present, are usually iatrogenically produced following a surgical procedure or percutaneous coronary intervention6

Armsby et al reported that $39 \%$ of patients are symptomatic, with palpitations, dyspnea on exertion, effort angina, etc? Origin from the left coronary artery is more common than from the right $(66.6 \%)$. We have report a case of dilated cardiomyopathy (DCM) caused by a coronary-pulmonary fistula, which was successfully treated with coils. Coronary fistulae and coronary-steal-induced ischemia are rare causes of DCM in adults with normal coronary arteries? The present case suggests that a CAF arising before a coronary stenosis may contribute to the genesis of myocardial ischemia, perhaps by giving rise to a steal phenomenon.

Currently there are 3 management options available for CAF. First, small asymptomatic CAF may be managed conservatively, not only because small and hemodynamically inconsequential CAF generally run a benign course but also because small CAF may close spontaneously? The second therapeutic option is surgical closure, which, although safe and effective with a high closure and survival rate, still has

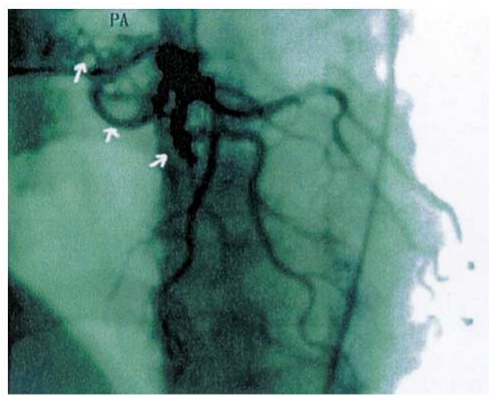

A

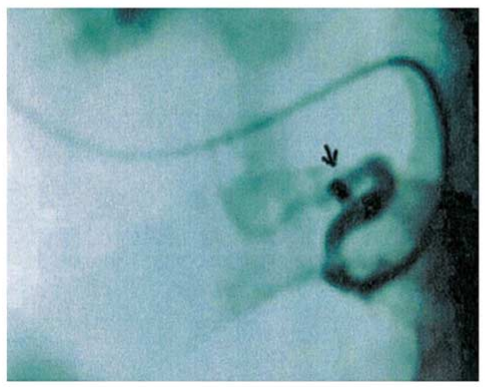

C

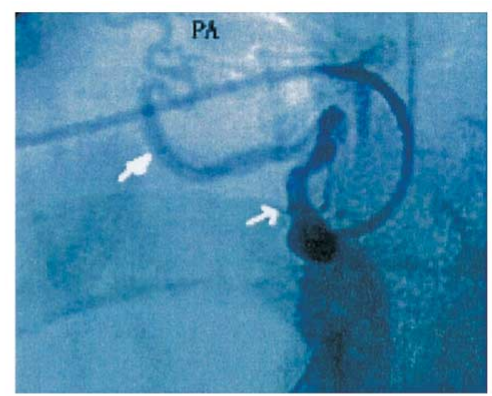

B

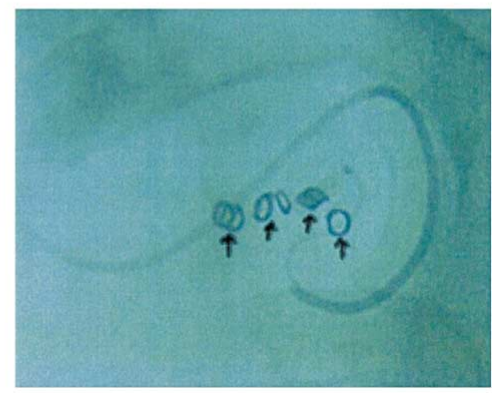

D

Fig 4. (A-D) Coronary angiography and transcatheter closure with coils. White arrows show the coronary-pulmonary fistula and black arrows show the coils. PA, pulmonary artery. 

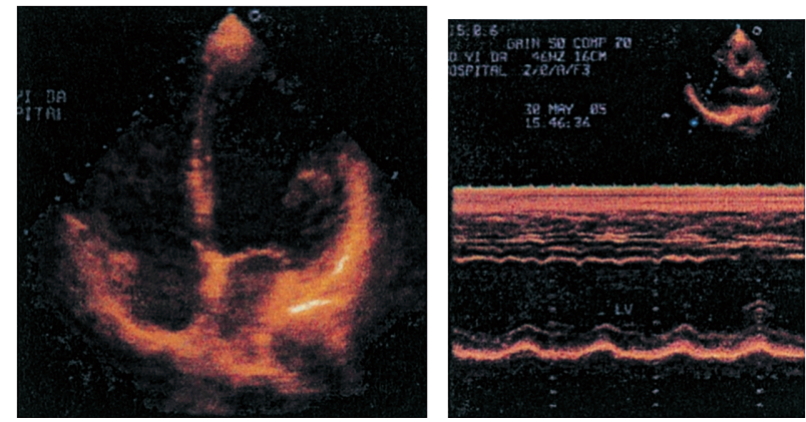

Fig 5. Echocardiography findings (3 months post-operation).

the risk of myocardial infarction or recurrence ${ }^{10}$ The third therapeutic option is percutaneous transcatheter closure. In our opinion, the majority of CAF can and should be managed by percutaneous techniques initially, even if staged procedure is ultimately required. Transcatheter closure of $\mathrm{CAF}$ is safe and feasible in anatomically suitable vessels.

\section{References}

1. Sunder KR, Balakrishnan KG, Tharakan JA, Titus T, Pillai VR, Francis B, et al. Coronary artery fistula in children and adults: A review of 25 cases with long-term observations. Int J Cardiol 1997; 58: $47-53$.

2. Vavuranakis M, Bush CA, Boudoulas H. Coronary artery fistulas in adults: Incidence, angiographic characteristics, natural history. Cathet Cardiovasc Diagn 1995; 35: 116-120.

3. Reidy JF, Sowton E, Ross DN. Transcatheter occlusion of coronary to bronchial anastomosis by detachable balloon combined with coronary angioplasty at same procedure. Br Heart J 1983; 49: 284-287.

4. Calder AL, Co EE, Sage MD. Coronary arterial abnormalities in pul-
Table 1 Changes in Hemodynamics and Blood Chemistry Before and After Coil Embolization of Coronary Artery Fistula

\begin{tabular}{lcl}
\hline \hline & Before treatment & After treatment \\
\hline PAP $(\mathrm{mmHg}$, by echo $)$ & 38 & 26 \\
$\mathrm{SaO} \%$-AO & 98.1 & 98.1 \\
$\mathrm{SaO} \%-P A$ & 82.6 & 79.2 \\
$\mathrm{SaO} \%-\mathrm{RA}$ & 78.1 & 78.6 \\
Shunt ratio $(\%)$ & 29.0 & 3.2 \\
Plasma BNP $($ fmol $/ \mathrm{ml})$ & 67.8 & $39.6(3$ months $)$ \\
Plasma Carnitine $(\mathrm{mg} / \mathrm{L})$ & 30.5 & $17.1(3$ months $)$ \\
\hline
\end{tabular}

PAP, pulmonary artery pressure; $\mathrm{SaO}_{2} \%$, oxygen saturation; $\mathrm{AO}$, aorta; $P A$, pulmonary artery; $R A$, right atrium; $B N P$, brain natriuretic peptide.

monary atresia with intact ventricular septum. Am J Cardiol 1987; 59: $436-442$.

5. Mavroudis C, Backer CL, Muster AJ, Pahl E, Sanders JH, Zales VR, et al. Expanding indications for pediatric coronary artery bypass. J Thorac Cardiovasc Surg 1996; 111: 181-189.

6. Baim D, Kline H, Silverman J. Bilateral coronary artery-pulmonary artery fistulas: Report of five cases and review of the literature. Circulation 1982; 65: 810-815.

7. Armsby LR, Keane JF, Sherwood MC, Forbess JM, Perry SB, Lock JE. Management of coronary artery fistulae: Patient selection and results of transcatheter closure. J Am Coll Cardiol 2002; 39: 10261032.

8. Fiocca L, Clerissi J, Bronzini R, Zumbo F, Di Biasi M, Montenero AS. Myocardial ischemia due to a coronary-pulmonary fistula treated with coil embolization. Ital Heart J 2004; 5: 551-553.

9. Hackett D, Hallidie-Smith KA. Spontaneous closure of coronary artery fistula. Br Heart J 1984; 52: 477-479.

10. Mavroudis C, Backer CL, Rocchini AP, Muster AJ, Gevitz M. Coronary artery fistulas in infants and children: A surgical review and discussion of coil embolization. Ann Thorac Surg 1997; 63: $1235-1242$. 